\title{
APLIKASI PENGELOLAAN DATA PENGUJIAN JELLY STRENGTH DAN WHITENES PADA INDUSTRI SURIMI PT.KELOLA MINA LAUT TUBAN
}

\author{
Nur Arini ${ }^{1)}$ Muhyiddin Zainul Arifin ${ }^{2)}$, Agus Sifaunajah ${ }^{3)}$ \\ 1) e-mail : arinimrf@gmail.com \\ 2) e-mail : muhyiddin_arifin@yahoo.co.id \\ ${ }^{3)}$ E-mail : agus.syifa85@gmail.com
}

\begin{abstract}
PT Manage Mina Seafood is a company working in the field of fisheries, particularly the freezing of fish that can be called by the term surimi ,

Grade is the emergence of a value of the test results together with the final result, RM or raw material or also called the raw material is bad it will display the grade with a low value, low value is impacting the sales price is very cheap, the testing manual systems are still so simple when compared with the progress of this company in this program I am using Java .

Therefore I strive to create an effective new system more attractive and long term for the company, for my research this time I can give results in value can make progress on the company and accepted by the company PT.KML .
\end{abstract}

Keywords : Surimi , Jelly strength, Grade, Java 


\section{Pendahuluan}

Perkembangan Informasi Teknologi saat ini semakin mengalami perkembangan yang sangat pesat. Banyak aplikasi-aplikasi yang canggih terus bermunculan untuk membentuk kegiatan manusia diseluruh muka bumi ini. Pada aplikasi yang akan dibuat ini membahas bagaimana cara mempermudah karyawan agar mampu bekerja dengan lebih efisien dan secara mudah untuk memberikan data dengan lebih cepat ,yaitu dengan sistem penginputan data yang berbentuk struk data print out.

\section{Kerangka Teori}

\subsection{Landasan Teori}

Lucas (1993 : 5) mengungkapkan bahwa, "Sistem merupakan suatu himpunan atau variabel yang terorganisasi, saling berinteraksi, saling bergantung satu sama lain dan terpadu".

Berbagai ahli telah mengajukan beberapa daftar sebagai dasar bagi teori sistem umum diantaranya :

1. Komponen-komponen sistem saling berhubungan dan tergantung satu salain.

2. Sebuah sistem harus dipandang sebagai satu keseluruhan.

3. Sistem adalah pengejar sasaran dalam beberapa cara. Komponen yang saling berinteraksi mencapai beberapa sasaran yaitu sebuah keseimbangan pencapaian tujuan.

4. Sistem mempunyai input dan output.

5. Semua sistem mengubah input menjadi output.

Sistem menunjukan adanya entropi. Entropi menunjukan keadaan sistem tertutup (tidak ada input dari luar sistem) dimana tiap elemen bergerak menuju ke keadaan tidak terorganisasi dan ketidakmampuan untuk mendapatkan serta mengolah input sehingga sistem tersebut tidak sanggup menghasilkan output.

\subsection{Pustaka Rujukan}

Database merupakan komponen terpenting dalam pembangunan sistem informasi, karena menjadi tempat untuk menampung dan mengoperasikan seluruh data yang ada dalam sistem, sehingga dapat dieksplorasi untuk menyusun informasi-informasi dalam berbagai bentuk. Data tersebut diorganisasikan sedemikian rupa agar tidak terjadi duplikasi yang tidak perlu, sehingga dapat diolah atau dieksplorasi secara cepat dan mudah untuk menghasilkan informasi. [5]

Database adalah sebuah perangkat lunak yang dirancang dan diperuntukkan sebagai media untuk menyimpan data-data transaksi yang dihasilkan pada sebuah proses bisnis. Database minimal terdiri dari satu file yang cukup untuk dimanipulasi oleh komputer sedemikian rupa.

Dari beberapa pengertian diatas dapat disimpulkan bahwa database merupakan perangkat lunak yang digunakan untuk menyimpan data.

\section{Metodologi Sistem \\ 3.1 Alat dan Bahan}

Bahan penelitian yang digunakan dalam proses penelitian ini berasal melalui wawancara pimpinan PT.KML Tuban, karyawan, supervisor, studi pustaka, jurnal, artikel dan buku pendukung.

Dalam melakukan penelitian ini, alat yang digunakan untuk keberhasilan penelitian adalah sebagai berikut :

Untuk mengiplementasikan program aplikasi sebuah perangkat keras harus memiliki spesifikasi sebagai berikut.

1. Prosesor intel core i3-23 10M Aspire 4750

2. Hardisk $500 \mathrm{~GB}$

3. Ram 2 GB DDR3 Memory 
Kebutuhan perangkat lunak

Hardware saja tidak dapat menyelesaikan masalah tanpa adanya software. Perangkat lunak yang di perlukan untuk menjalankan perangkat keras adalah sebagai berikut.

1. Sistem operasi windows ultimate 32 bit

2. Neatbeans IDE 8.0.2

3. Xampp control panel v3.2.1

4. MYSQL sebagai bahasa pemrograman untuk database dalam bahasa SQL (structural Query Language).

\subsection{Prosedur Penelitian}

Metologi yang digunakan untuk menganalisa permasalahan yang terkait dalam pembuatan sistem.

1. Studi Literatur

Mempelajari dan mengumpulkan data yang diambil dari buku-buku, internet dan wawancara.

2. Perancangan Sistem

Pada tahap ini dilakukan suatu perancangan system dari system penerimaan tenaga kerja yang masih manual di PT.KML TUBAN.

3. Implementasi Sistem

Tahap implementasi ini dilakukan ketika proses perancangan system sudah dilalui. Sistem pengelolaan data di implementasikan pada pemrograman bahasa $\mathrm{C}$ yaitu java

4. Pengujian Sistem

Pengujian system merupakan tahapan untuk mengetahui seberapa efektif dan efisien program yang dirancang dalam mencapai sebuah sasaran yang diharapkan.

5. Dokumentasi

Tahap dokumentasi merupakan tahap yang dilakukan untuk memberikan informasi terhadap sistem yang telah dirancang dan di implementasikan serta telah di uji kepada pihak-pihak yang membutuhkan.

6. Pengelolaan data manual

Berikut ini adalah gambaran secara umum proses sistem pengendalian aset dengan sistem lama :

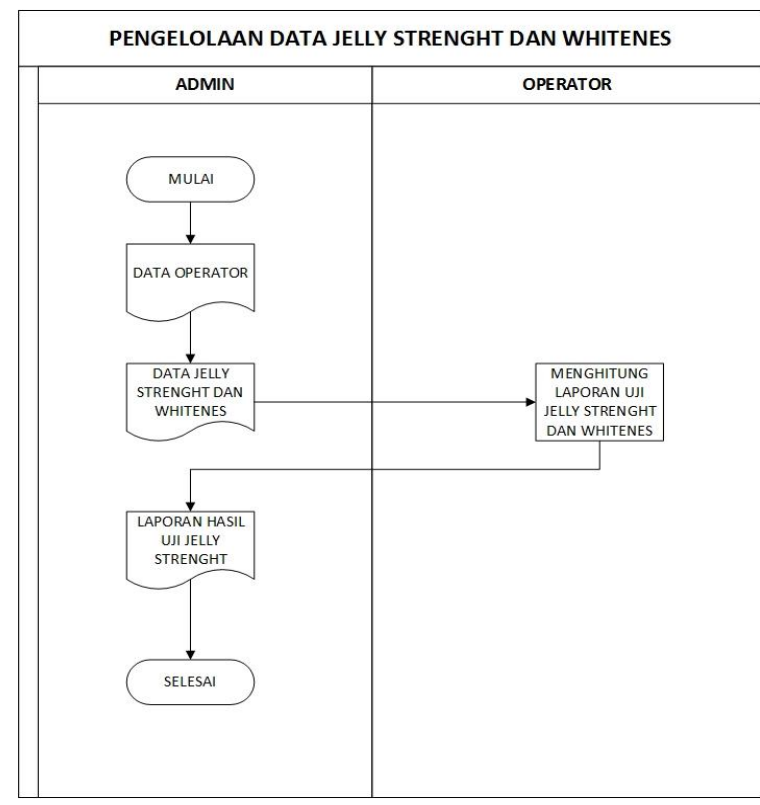

\section{Gambar 3.2 Flow of Manual Documents sistem lama Pengelolaan Uji Jelly Strenght dan Whiteness}


Sistem lama yang digunakan PT. Pengelolaan Uji Jelly Strenght dan Whiteness:

a) Operator masuk ke sistem dengan menggunakan username dan password yang dimiliki.

b) Memasukan nilai uji jelly strength dan whiteness.

c) Menghitung laporan uji jelly strength dan whiteness .

d) Hasil proses uji jelly strength san whiteness selesai.

e) Hasil proses uji tersebut di laporkan oleh atasan.

7. Flow of Manual Documents Sistem Baru

Berikut ini adalah gambaran secara umum proses sistem pengelolaan data uji jelly strengt dan whiteness dengan sistem baru admin beserta operator.

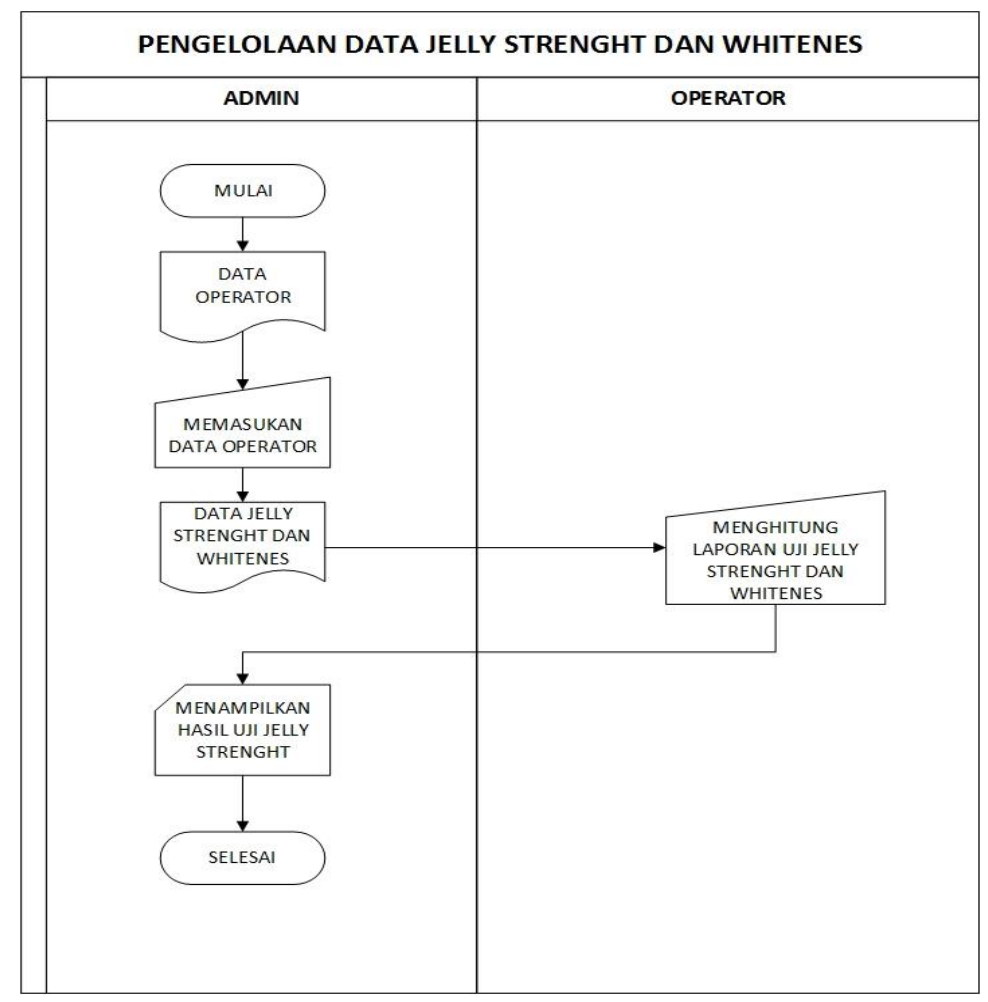

\section{Gambar 3.3 Flow of Manual Documents sistem baru pengelolaan uji jelly strength dan whiteness}

Sistem baru yang digunakan PT. KML TUBAN dapat dideskripsikan sebagai berikut :

a) Admin masuk kedalam sistem dengan menggunakan username dan password yang dimiliki, kemudian memasukan data hasil uji jelly strength dan whiteness.

b) Kepegawaian masuk kedalam sistem dengan menggunakan id pengguna dan password yang dimiliki.

c) Kepegawaian memasukan data uji jelly strength dan whiteness.

d) Kepegawaian memasukan perhitungan data uji jelly strength dan whiteness.

e) Menampilkan hasil uji jelly strength muncul dengan grade sesuai dengan nilainya 


\section{Hasil dan Pembahasan}

\subsection{Perancangan Interface Aplikasi}

1. Halaman Login

Merupakan tampilan awal yang digunakan Administrator dan Opeartor untuk masuk kedalam program aplikasi. Pada halaman ini terdapat pilihan level Administrator dan Opeartor untuk masuk kedalam program aplikasi. Berikut ini tampilan halaman login yang terlihat pada gambar 4.1 dibawah ini.

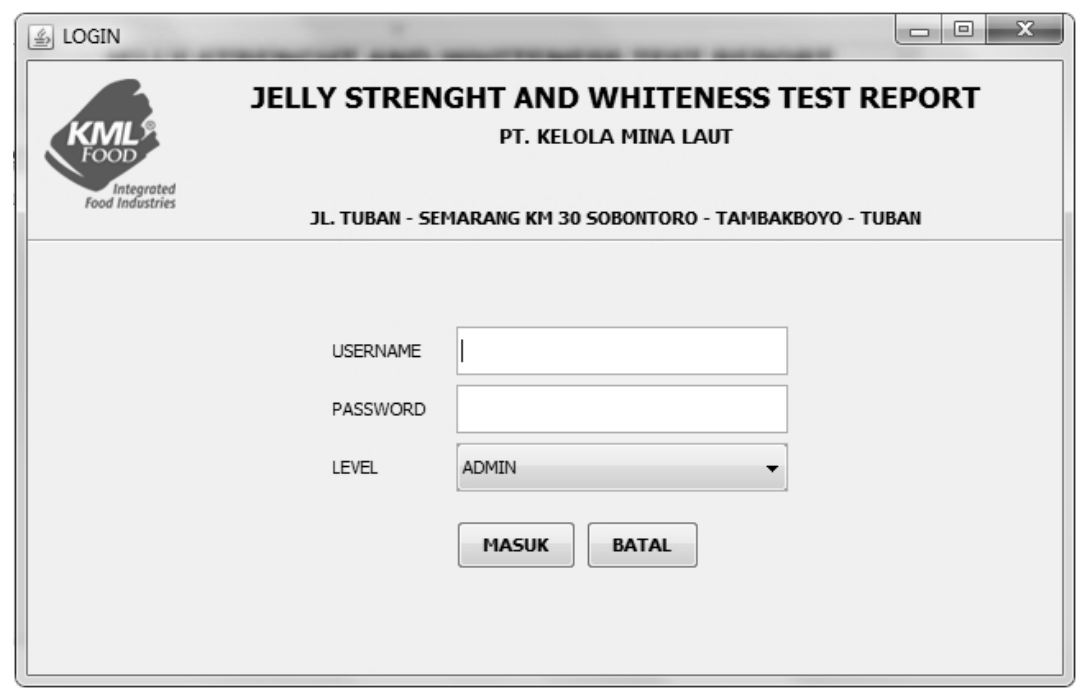

Gambar 4.1 tampilan halaman login

\section{Halaman Utama}

Merupakan tampilan utama setelah melakukan login, halaman utama memiliki akses yang digunakan Administrator dan Operator untuk melakukan.

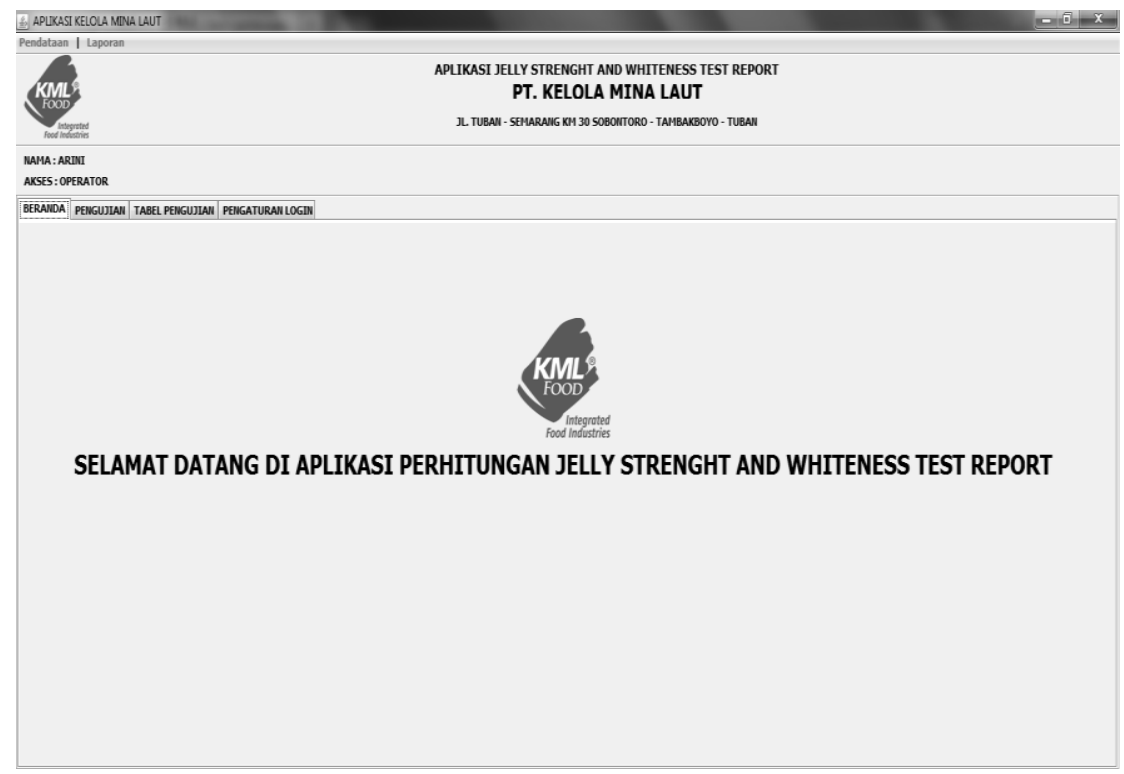

Gambar 4.2 Tampilan halaman utama 


\subsection{Perhitungan}

Berikut ini adalah rumus perhitungan dari jelly strength, dengan perhitungan ini akan diperoleh grade kualitas dari jelly strength.

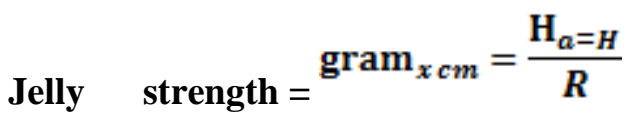

$\begin{array}{ll}\text { Gram } & =\text { berat tumpuhan } \\ \mathrm{Cm} & =\text { panjangnya tusukan untuk mnedapatkan kekenyalan } \\ \mathrm{Ha} & =\text { hasil analisa } \\ \mathrm{R} & =\text { rata- rata } \\ \mathrm{H} & =\text { hasil dari keseluruhan hingga mendapatkan grade }\end{array}$

\section{Penutup}

\subsection{Kesimpulan}

Setelah dilakukan analisa, perancangan dan pembuatan aplikasi system informasi aplikasi pengelolaan data jelly strenght dan whitenes berbasis java pada industri surimi PT.KML Tuban dapat diambil beberapa kesimpulan sebagai berikut :

1. Sistem Informasi yang dibangun dapat membantu peningkatan kinerja yang relative lebih baik dan aman bagi pengguna.

2. Sistem Informasi yang dibangun dapat mempermudah dan mempercepat kinerja pegawai karena dengan adanya system aplikasi ini operator dapat menginputkan hasil uji secara konsisten.

\subsection{Saran}

Berdasarkan hasil penelitian, berikut ini adalah saran yang sebaiknya dilakukan guna pengembangan system ini menjadi lebih baik :

1. Sistem Informasi aplikasi pengelolaan data jelly strenght dan whitenes berbasis java pada industri surimi PT.KML Tuban ini dapat dikembangkan seiring dengan perkembangan spesifikasi kebutuhan pengguna Sistem.

2. Sistem aplikasi pengelolaan data jelly strength dan whiteness berbasis java ini dapat dikembangkan dengan menambahkan menu standart harga food grade dari harga rendah tingginya jelly strength.

\section{DAFTAR PUSTAKA}

Departemen Dalam Negeri (2007). Peraturan Menteri Dalam Negeri Republik Indonesia Nomor 17 tahun 2007 tentang pedoman teknis pengelolaan barang milik daerah. Jakarta.

Gustafson, David. 2002. Schaum's Outlines - Software Engineering. Halaman 1 halaman 6.

Graha Ilmu Yogyakarta : Andi. 2007:75

Hasan 2004:65. Definisi Keputusan. Jakarta : Ghalia Indonesia.

Hasan 2004:49. Definisi Pengambilan Keputusan. Jakarta : Ghalia Indonesia.

Haryono Jusup 2005:165. Metoda - Metoda Depresiasi.

Jogianto, H.M. 2005. Analisis dan Desain Sistem Informasi. Yogyakarta: CV. Andi Offset 
Kusumadewi. Fuzzy Multi-Atribute Decission Making (Fuzzy MADM). Yogyakarta : Andi. 2006:74

Kusumadewi. Langkah-langkah penelitian dalam menggunakan metode Simple Additive Weighting (SAW). Yogyakarta : Andi. 2006:75

Kusumadewi. Algoritma Simple additive weighting (SAW).

Turban, Aranson. Decission Support System and Intelligent System $-77^{\text {th }}$ Ed. Jilid 1(Sistem Pendukung Keputusan dan Sistem Cerdas). Yogyakarta : Andi. 2005:47

Mary Follet. Keputusan adalah suatu atau sebagai hukum situasi. Hasan, 2004:65.

Turban, Aranson. Decission Support System and Intelligent System $-77^{\text {th }}$ Ed. Jilid 2(Sistem Pendukung Keputusan dan Sistem Cerdas). Yogyakarta : Andi. 2005:47 